\title{
IDENTIDADE E REGIÃO EM "QUADRAS AO RORAIMEIRA"
}

\author{
IDENTITY AND REGION IN "QUADRAS AO RORAIMEIRA"
}

\section{Valtenir Soares de Abreu ${ }^{1}$ Adriana Helena de Oliveira Albano ${ }^{2}$}

Resumo: este artigo tem como objetivo principal apresentar uma parcela da produção literária cordelística de Rodrigo Oliveira por meio do cordel "Quadras ao Roraimeira" (2010), pela metodologia da análise crítica. Como problema, buscamos compreender algumas características do gênero com a ideia de uma identidade roraimense construída por meio do cordel supracitado. Os principais pressupostos são as noções de Bourdieu (2012) a respeito das representações simbólicas na formação das identidades regionais, e de território legitimado, além da concepção de identidade trabalhada por Hall (2006), que considera as identidades resultados, entre outros fatores, de influências, de negociações e de diferenças.

Palavras-chave: cordel; identidade; região; Roraima.

Abstract: This article aims to present a portion of Rodrigo Oliveira's cordelistic literary production through the cordel "Quadras ao Roraimeira" (2010), using the critical analysis methodology. As a problem, we seek to understand some characteristics of the genre with the idea of a Roraima identity constructed through the aforementioned cordel The main assumptions are Bourdieu's (2012) notions about symbolic representations in the formation of regional identities, and of legitimated territory, in addition to the conception of identity worked by Hall (2006), which considers the identities results, among other factors, of influences, negotiations and differences.

Keywords: cordel; identity; region; Roraima.

\section{Introdução}

A literatura hoje conhecida como cordel chegou às terras brasileiras e se desenvolveu com maior intensidade em alguns estados da Região Nordeste do país. Posteriormente, foi distribuída por outras regiões, tornando-se, dessa forma, uma expressão literária popular de significativa importância como elemento simbólico de cultura.

\footnotetext{
${ }^{1}$ Doutorando do Programa Interdisciplinar de Linguística Aplicada da Universidade Federal do Rio de Janeiro (UFRJ). Mestre em Letras: Literatura, Cultura e Identidade, pela Universidade Federal de Roraima (UFRR). Graduado em Pedagogia pela Universidade Estadual de Roraima. Tem experiência em Educação Inclusiva, Educação de Jovens e Adultos e Tecnologias Educacionais. Atualmente, trabalha como Técnico em Assuntos Educacionais na Universidade Federal de Roraima, além de colaborar na organização de eventos e livros. E-mail: valtenir_abreu@outlook.com

2 Pós-doutora pela UFRR (2013), doutora pela UNESP (2010). Autora dos livros O Pilão de pilar lembranças: Teoria Poética e Rastros de Memória, possui experiência na área de Teoria Literária e Educação, com ênfase em Crítica Literária e Memória Cultural. Atualmente é e professora adjunta da Universidade Federal de Roraima e Supervisora do Programa Residência Pedagógica e atua em projetos de pesquisa e extensão. E-mail: drikaalbano@yahoo.com
} 
Nesse contexto, de representação cultural de determinada região, este artigo tem como objetivo principal apresentar uma parcela da produção literária cordelística de Rodrigo Oliveira, por meio da metodologia da análise crítica do cordel "Quadras ao Roraimeira" (2010). O problema que circunda a construção do presente texto é a relação existente entre a produção supracitada e as noções de identidade e região, tendo em vista que o cordel figura como produção popular, símbolo da busca do ser pela identificação com o lugar onde habita ou do qual é originário.

Propomos uma leitura das imagens propostas pela performance do gênero de cordel articuladas à ideia de uma identidade roraimense elaborada no texto aqui estudado. Para tanto, utilizamos como principais pressupostos teóricos as noções de Bourdieu (2012) a respeito das representações simbólicas na formação das identidades regionais, e de território legitimado, além da concepção de identidade trabalhada por Hall (2006), que considera as identidades resultados, entre outros fatores, de influências, de negociações e de diferenças.

Antes, em busca de compreender o processo de sua constituição e a forma como atualmente a Literatura de Cordel se apresenta no estado de Roraima, elaboramos um pequeno apanhado histórico dessa literatura, assumindo a ideia de que os folhetos - outro nome pelo qual os cordéis são conhecidos - seriam originários das antigas narrativas orais da Península Ibérica, tendo passado por alterações e adaptações até consolidar-se em solo brasileiro. Nessa construção, utilizaremos principalmente os autores Andrade (2005), Galvão (2006) e Saraiva e Lopes (1989), estudiosos que se dedicaram à pesquisa do trajeto cordelístico pela história.

\section{Breve histórico do cordel}

Apesar de não haver consenso quanto à origem, críticos do gênero cordel, como Ana Maria Galvão (2006) e Moreira de Acopiara (2009), trabalham com a noção de que a história da Literatura de Cordel guarda relação com as tradições orais da Europa, mais precisamente da Península Ibérica, nos séculos XI e XII. Galvão (2006), analisando o percurso histórico dessa literatura, propõe que:

... o que parece sensato afirmar é que é inegável a influência do cordel português na constituição da literatura de folhetos brasileira. Essa fonte foi, evidentemente, associada a outras influências, como a forma de poesia oral, ao hábito de se transmitir o patrimônio cultural através de histórias, aos pregões, e a outros modos de oralidade comuns em uma sociedade, como a do Brasil imperial, com baixos índices de letramento. (GALVÃO, 2006, p. 30).

Segundo a autora, apesar de o cordel trazer influências variadas em sua constituição, passando, portanto, a apresentar características próprias, de acordo com sua inserção cultural - 
essa é a questão que mais nos interessa aqui, na medida em que o cordel analisado neste trabalho foi produzido na região norte e traz influências da produção literária local - a relação deste com o cordel português não pode ser negada, pois os traços de uma poética voltada para oralidade e de constituição narrativa proveniente de além mar está presente até nas produções atuais.

Nascida como poesia narrativa e de caráter popular - forma de manifestação que mais tarde ganharia uma versão escrita -, esteve, na maior parte do tempo, a serviço das classes sociais menos favorecidas, isoladas das cidades principais e, por esse motivo, privadas das notícias e fatos marcantes (GALVÃO, 2006).

Nesse sentido, uma poesia de caráter oral, que favorecesse o contato, ainda que indireto, desses grupos com o mundo exterior, não demoraria a cair no gosto popular, tornando-se um alento, uma forma de identificação das pessoas, que passariam a ter uma voz que as representasse (ANDRADE, 2005).

Já Andrade (2005), ao analisar historicamente o cordel, lança um olhar às antigas tradições populares da Idade Média, de onde originalmente seriam provenientes os nossos atuais folhetos. A propósito de compreender a cronologia dessa literatura, afirma o escritor:

Nesses primeiros séculos, a literatura popular foi obra de diversos tipos de artistas, entre os quais destacamos os trovadores, os jograis e os menestréis. Eram cantores ou poetas andarilhos, que viajavam de corte em corte, de cidade em cidade, divertindo o povo, os nobres e os reis com sua arte, que combinava poesia, música, mímica e drama, e era, ao mesmo tempo, divertimento e informação. (ANDRADE, 2005, p. 128)

Os artistas eram aguardados com muita ansiedade pelos habitantes dos feudos. O fato de viajarem muito, de estabelecerem contato com outras comunidades, outras cidades, conferialhes o status de mensageiros, emissários de boas novas, sempre com muitas histórias para contar, ou seja, sua arte estava a serviço dos que não podiam ausentar-se dos seus locais de moradia, a não ser em casos extremos, como guerras ou peregrinações religiosas.

Mas essa tradição, para consolidar-se como tal, recebeu influências de outras terras, desde elementos da civilização cristã até manifestações culturais dos árabes, que dominaram a Península Ibérica por oito séculos (ANDRADE, 2005). Os artistas se faziam acompanhar de instrumentos musicais, o que colabora para que Andrade (2005) acredite que teria nascido daí a dinâmica de apresentação dos cantadores brasileiros, cuja poesia se assemelha à da Literatura de Cordel, inclusive por serem ambas tributárias das tradições orais. Para Andrade:

Além desses elementos de origem europeia (e ligados à civilização cristã), a cultura popular de Espanha e Portugal recebe ainda grande influência dos árabes, que durante oito séculos dominaram a Península Ibérica.

Entre os seguidores do Islã existiam também poetas cantadores, os "medajs", que se apresentavam em praça pública, cantando velhos contos de origem asiática (persas ou 
hindus) ou ainda celebrando a memória e divulgando os feitos heroicos de seus guerreiros. Nesses cantos, os "medajs" se faziam invariavelmente acompanhar de instrumentos musicais como adufes, castanholas, alaúdes e rabecas.

Essas duas tradições de artistas populares - de um lado trovadores, jograis e menestréis e, de outro, os "medajs" muçulmanos - fundiram-se na tradição da cultura portuguesa e podem ser considerados os ancestrais de uma arte popular hoje perpetuada por nossos violeiros repentistas e poetas populares. (ANDRADE, 2005, p. 129-130)

Os escritores António José Saraiva e Oscar Lopes, no Livro História da Literatura Portuguesa (1989), fazem uma análise importante do percurso da literatura, desde sua predominância oral até sua migração para a forma escrita. Os autores citam, por exemplo, a importância dos jograis-recitadores, cantores e músicos ambulantes, cujo trabalho era a divulgação de um repertório musical e literário no qual a participação dos ouvintes fazia toda a diferença, ou seja, era o principal estímulo. (SARAIVA \& LOPES, 1989, p. 35)

Além destes, outros personagens, como os pregadores eclesiásticos, também merecem destaque, pois a estes cabia a tarefa de levar às massas populares o saber que até então era privilégio de poucos, por constar nos livros, aos quais a maioria da população não tinha acesso.

Os autores portugueses apontam que os mais antigos textos literários em língua portuguesa são composições em verso, de fins do século XII e do século XIV. Antes do surgimento de qualquer forma de escrita, as histórias, narrativas e até mesmo códigos morais se fixavam na memória dos ouvintes, que os recebiam por intermédio de artistas encarregados especificamente dessa divulgação. Os gregos os conheciam como aedos e rapsodos, os celtas os chamavam de bardos e os povos românicos medievais tinham os jograis. (SARAIVA \& LOPES, 1989)

Ainda em princípios do século XII, iniciou-se um processo de adaptações na poesia folclórica, ficando assim as formas mais simples, versificadas, destinadas ao tratamento das questões rurais e primitivas, enquanto as mais complexas, formadas a partir daquelas, se encarregariam dos temas burgueses e cortesãos (SARAIVA \& LOPES, 1989).

Nessa trajetória, de acordo com Manuel Diegues Jr. (1973) a poesia medieval, guardando semelhanças com o que se conhece atualmente por Literatura de Cordel, teria chegado ao Brasil, dentro da bagagem dos colonizadores; em sua maioria, em grupos formados por militares, estudantes, intelectuais, literatos, poetas, ou seja, um vasto contingente de apreciadores de poesia. "Nas naus colonizadoras, com os lavradores, os artífices, a gente do povo, veio naturalmente a tradição do Romanceiro, que se fixaria no Nordeste do Brasil, como Literatura de Cordel.” (DIEGUES JR., 1973, p. 5) 
Trazendo em sua constituição toda a riqueza das influências recebidas ao longo dos séculos, como as temáticas ligadas a temas religiosos, satíricos ou românticos, a dinâmica de preservação da memória cultural e a proximidade com os grupos menos letrados e menos abastados da sociedade, a Literatura de Cordel chega ao Brasil em meados do século XVI e início do século XVII, juntamente com os colonizadores portugueses.

Tal como sua ascendente portuguesa, o cordel no Brasil ressurge das manifestações orais, ganhando depois uma versão escrita, que busca, na medida do possível, conservar a proximidade com a linguagem popular, mais presente nos contextos de fala das regiões interioranas brasileiras. Não é outra a razão de tal ligação, senão o próprio fato de que as histórias narradas, que deram origem aos folhetos, provêm das tradições populares, como o modo de falar, os costumes, a religiosidade e a percepção do mundo. No cordel "Quadras ao Roraimeira" (2010), o cotidiano e a paisagem local são marcas da identidade construída. Esses elementos característicos apresentam e constroem relações simbólicas de identidade e região.

Entretanto, o crescimento dessa literatura demorou algum tempo para se consolidar, encontrando na região hoje chamada de Nordeste um terreno propício a sua ascensão. Sobre esse fato, Andrade (2005) afirma que:

Curiosamente, só três séculos depois da chegada desses livretos importados e do aparecimento dos nossos próprios artistas populares, lá pelo fim do século XIX, é que surgiram os primeiros folhetos de autoria de poetas brasileiros, na Região Nordeste do país. (ANDRADE, 2005, p. 131)

Tendo, portanto, encontrado no Nordeste um ambiente propício ao seu desenvolvimento, os folhetos transformaram-se em importante marca da cultura regional nordestina; o fortalecimento desse gênero em tais terras se deve, inclusive, às semelhanças iniciais com o contexto medieval europeu, de isolamento, a distância em relação aos centros urbanos e o pouco acesso à cultura letrada (GALVÃO, 2006).

Poetas e cantadores, a exemplo dos trovadores ibéricos, tornaram-se as personalidades desse momento de nascimento do cordel, que historicamente se constitui uma importante manifestação da cultura nordestina, conforme afirma Batista (1997):

No Nordeste, por condições sociais e culturais peculiares, foi possível o surgimento da Literatura de Cordel, da maneira como se tornou hoje em dia, característica da própria fisionomia da região. Fatores de formação social contribuíram para isso: a organização da sociedade patriarcal; o surgimento de manifestações messiânicas; o aparecimento de bandos de cangaceiros ou bandidos; as secas periódicas provocando desequilíbrios econômicos e sociais; as lutas de famílias que deram oportunidade, entre outros fatores, para que se verificasse o surgimento de grupos de cantadores como instrumento do pensamento coletivo, das manifestações da memória popular. (BATISTA, 1997, p. 74) 
Essa chegada ao Brasil, mais especificamente à Região Nordeste, conferiu aos folhetos uma característica peculiar, relacionada ao modo de vida, à forma de falar e, talvez, ao aspecto mais importante, a sua composição em forma de verso, o que facilita para as pessoas iletradas - maioria dos sertanejos - a memorização das histórias contadas.

As rimas, o ritmo, a musicalidade, as repetições e a busca pela proximidade com a linguagem falada transformaram a poesia em um texto mais acessível que a prosa, formato utilizado nos folhetos portugueses.

De acordo com Andrade (2005, p. 132), “O cordel em prosa, que existe em Portugal, contando vidas de santos, compondo almanaques e peças de teatro, entre nós nunca se desenvolveu". O autor atribui essa dessemelhança à própria constituição social do contexto brasileiro no qual o cordel se desenvolveu. Formado em sua maioria por pessoas iletradas, o povo das áreas sertanejas não tinha como acessar o texto escrito, ficando, dessa forma, dependente da própria memória para a conservação das histórias.

Ora, a poesia é um tipo de linguagem carregada de elementos que favorecem a memorização: as rimas, o ritmo, as repetições, a musicalidade, todos esses traços que marcam a poesia e ajudam o ouvinte a decorar o texto. Assim, nosso cordel, produzido e consumido por sertanejos de poucas letras, especializou-se em poesia, e mais especificamente, na sua forma narrativa. (ANDRADE, 2005, p. 132)

Os poetas também criaram seus próprios temas, inspirados no cotidiano da gente humilde e simples dos sertões. Tomando como base os acontecimentos e feitos de personagens da nossa história e utilizando ainda o rico folclore brasileiro. Uma das temáticas exploradas com frequência é a saga do cangaço, que tem na pessoa de Lampião o seu principal personagem. De acordo com Haurélio (2013), "são incontáveis as histórias que envolvem Virgulino Ferreira da Silva, o Lampião (1898 a 1938), o mais famoso bandido da história do Brasil”" (HAURÉLIO, 2013, p. 67).

Esses artistas da poesia fizeram surgir uma infinidade de assuntos para os folhetos, conforme tais temas. Logo, encontram um público cativo, identificado nas histórias, reconhecedor dos cenários e, portanto, fiador dessa forma poética que exprime suas características, seus sofrimentos e sua visão do mundo. Sobre essa relação do cordel com seu público, Andrade (2005), reflete:

Em sua origem, o cordel é um pouco de drama, ou espetáculo ritual que afirma os laços da coletividade, reforça a experiência comunitária. Como num banquete, o poeta e o público partilham os desejos e sonhos na forma de aventuras e emoções. Seja apenas recitando ou dedilhando as cordas da sua viola, esses artistas tocam as cordas do coração do público, e o rito coletivo faz reviver e atualizar uma antiga tradição. Nesse instante mágico, várias gerações e diferentes culturas dão-se as mãos num imenso cordão que multiplica e fortalece os laços da vida (ANDRADE, 2005, p. 135). 
As palavras de Andrade (2005) apresentam a razão pela qual o público da Literatura de Cordel se mantém em uma postura de fidelidade e de relação de respeito, de pertencimento, de identificação com os elementos e temáticas presentes nos textos. Trata-se de uma espécie de ritual que, passado de geração para geração, contribui para o fortalecimento da imagem e do discurso do "ser nordestino", da identidade simbólica negociada, pois "Todos os termos da identidade dependem do estabelecimento de limites - definindo o que são em relação ao que não são" (HALL, 2003, p. 85).

Conforme anteriormente discutido, a Literatura de Cordel atingiu estados de outras regiões do Brasil, após sua consolidação no Nordeste. Para efeito do presente trabalho, faremos, a seguir, um breve estudo sobre a presença dos folhetos no estado brasileiro de Roraima, localizado no extremo norte do país, com vistas a compreender o modo como se deu a entrada dessa literatura no contexto roraimense, bem como as principais temáticas discutidas e sua relevância para a discussão da identidade cultural roraimense.

\section{Literatura de Cordel em Roraima}

Como consequência do fortalecimento da Literatura de Cordel e sua consequente presença em estados brasileiros, fora da Região Nordeste, essa expressão literária chega também ao estado de Roraima, localizado na Região Norte e formado, predominantemente, a partir de correntes migratórias provenientes de outras partes do país. Constitui-se, desse modo, em ponto de encontro de várias manifestações culturais, tornando sua identidade híbrida, plural.

Uma pesquisa realizada pelo Centro de Recepção e Triagem de Migrantes (CETREMI), relativa ao período de novembro de 1981 e outubro de 1984, revela que, de todas as regiões brasileiras, o Nordeste foi a que mais enviou migrantes para o Estado de Roraima, com destaque para o Maranhão, estado então conhecido por apresentar importantes problemas fundiários (BARBOSA, 1993).

Analisando a questão sob outro prisma, o das relações interculturais estabelecidas no contexto no novo estado, pode-se perceber que as correntes migratórias configuraram uma diversificada rede de influências e manifestações, uma vez que cada um desses grupos trouxe consigo os traços de identificação com seus locais de origem, o que não os impede de construir novas experiências nos locais para onde migram. 
Nesse espaço, podemos dizer que os cordéis produzidos pelo escritor Rodrigo de Oliveira $(2017)^{3}$ versam sobre os mais variados temas, como é próprio da natureza dessa literatura, a qual carrega em si a possibilidade de tratar de assuntos que falam ao imaginário popular, gerando proximidade e possíveis identificações. Ao cordelista, observador da dinâmica social, dos acontecimentos, a busca por temas para suas rimas se encontra entre o povo, que se percebe inserido em sua produção e, no caso do presente estudo, propõe a construção simbólica da identidade regional roraimense.

Uma vez que o cordel é literatura popular, é de fato nos temas regionais que o poeta cordelista busca inspiração para escrever seus versos. De acordo com Galvão (2009), quando se procede a uma análise dos próprios cordéis, é possível perceber que, em muitas ocasiões, o poeta assumia o papel de porta-voz das novidades. A autora afirma que "muitas histórias... foram escritas a partir de notícias de jornais, que o poeta, habilmente, transformava em narrativa em versos" (GALVÃO, 2006, p. 182).

Pode-se perceber, nesse sentido, a preocupação do autor em atribuir aos seus textos uma determinada "cor local", ou seja, antes de escrever, o cordelista busca conhecer a realidade que deseja retratar, proporcionando ao leitor a oportunidade de conhecer e re-conhecer a cultura roraimense pela Literatura de Cordel.

A afluência de correntes migratórias provindas, em sua maioria, da Região Nordeste, contribuiu para a formação, no estado de Roraima, de uma cultura marcada pela diferença. Isso ocorreu na medida em que tais grupos trazem em si os traços culturais de seus locais de origem e passam a conviver em um espaço no qual transita uma gama de influências indígenas.

Ao ler os cordéis do autor estudado aqui, é possível perceber a preferência do poeta em descrever o cenário natural, as belezas, os mitos e lendas indígenas, aliando-se, dessa forma, a uma corrente de pensamento que objetivou repensar a identidade cultural do estado, encabeçada principalmente pelo Movimento Cultural Roraimeira, na década de 1980, que descreveremos adiante.

Nesse espaço híbrido, culturalmente diversificado, a Literatura de Cordel também tem seu espaço reivindicado, através da produção de alguns textos nesse formato, destacando-se principalmente Rodrigo de Oliveira, uma vez que apresenta maior volume de produções, que em sua maioria, são voltadas à divulgação e valorização da cultura roraimense e de sua

\footnotetext{
${ }^{3}$ Na revisão do artigo, optamos por incluir esta obra de Rodrigo de Oliveira publicada recentemente. Ela reúne os cordéis já publicados em folhetos e aqueles encontrados em ambiente virtual. Atentamos para o fato de que alguns cordéis foram reescritos e ampliados para a versão do livro.
} 
expressão indígena, podendo citar também o longo cordel "O código de Makunaima" (OLIVEIRA, 2017, p. 15), em que o autor descreve um encontro mítico entre o escritor Mário de Andrade e a divindade indígena Makunaima, "O encontro de Makunaima com Ajuricaba: contra a biopirataria" (p. 73), em que há a descrição das espécies vegetais da região e um grito de socorro para sua preservação e "Lavradeiro" (p. 49), em que é contada a história de personagens populares importantes na história da região.

Lembramos que no presente estudo, analisaremos apenas "Quadras ao Roraimeira", por acreditar que esse cordel expõe as características da obra do autor de um modo suficientemente produtivo para a análise proposta.

\section{Identidade e região em "Quadras ao Roraimeira"}

No cordel "Quadras ao Roraimeira" (OLIVEIRA, 2010), o poeta apresenta o acontecimento do movimento cultural "Roraimeira" articulando-o à caracterização do estado de Roraima por meio de elementos simbólicos da cultura. Ao homenagear o movimento cultural, o cordelista, ao mesmo tempo, trabalha com as representações que este trio de artistas articula na construção da identidade local, que, como afirma Hall (1996), são pontos cambiantes de identificação na medida em que assumem determinados posicionamentos,

As identidades culturais são pontos de identificação, os pontos instáveis de identificação ou sutura, feitos no interior dos discursos da cultura e história. Não uma essência, mas um posicionamento. Donde haver sempre uma política da identidade, uma política de posição, que não conta com nenhuma garantia absoluta numa lei de origem sem problemas, transcendental (HALL, 1996, p. 70).

O posicionamento que encontramos no cordel a ser analisado é de uma identidade nortista que reivindica seu reconhecimento por meio de elementos culturais ligados tanto aos artistas locais e suas representações, quanto aos elementos que compõem o cenário. De acordo com Wankler (2013), com base no discurso que descreve a exuberância da natureza e a diversidade de influências existente no estado, o "Roraimeira" desenha uma visão de identidade a partir desses fundamentos. A autora afirma:

\footnotetext{
Na década de 1980, o movimento cultural Roraimeira buscou discutir o problema da identidade cultural roraimense através da produção de uma arte profundamente vinculada ao ambiente local. A partir do Roraimeira, o uso dos elementos considerados caracterizadores da paisagem local nas artes tornou-se quase um estatuto, preocupado em reafirmar uma identidade: o "ser de Roraima". (WANKLER, 2013, p. 2)
}

Desse modo, o movimento entendeu a necessidade de criação, por meio da arte, dos símbolos da terra e dos costumes da região. O "Trio Roraimeira", constituído pelos artistas 
Eliakin Rufino, Zeca Preto e Neuber Uchôa, os três principais idealizadores do "Movimento Roraimeira" (WANKLER, 2013), se torna o responsável pela construção imaginária inicial da identidade roraimense, "Eliakim Rufino, filósofo, professor e poeta roraimense premiado nacionalmente e um dos líderes do 'Roraimeira', afirma que o movimento no estado foi uma espécie de Modernismo tardio" (p. 3).

Nessa perspectiva, entendemos que se buscou, assim como no Modernismo, uma arte que representasse o país, uma arte nacional/regional que não fosse a "cópia" do modelo europeu, como ocorreu, principalmente, no Romantismo. No caso de Roraima, o Estado vem colocar o espaço nortista como uma parte culturalmente significativa por guardar características peculiares, como a localização em tríplice fronteira (Brasil, República Cooperativa da Guiana e Venezuela), o fato de abrigar, proporcionalmente, a maior população indígena do Brasil (IBGE, 2012), com suas influências culinárias e culturais, além da realidade migratória. Assim, entendemos que a necessidade do estabelecimento dessa identidade regional, por meio da arte literária, vai ao encontro do que afirma Bourdieu (2012):

O autor, mesmo quando só diz com autoridade aquilo que é, mesmo quando se limita a enunciar o ser, produz uma mudança no ser: ao dizer as coisas com autoridade, quer dizer, à vista de todos, e em nome de todos, publicamente e oficialmente, ele subtraias ao arbitrário, sanciona-as, consagra-as, fazendo-as existir como dignas de existir, como conforme à natureza das coisas naturais (BOURDIEU, 2012, p. 114).

Nessa perspectiva, podemos dizer que a compreensão da realidade - aqui aplicada ao estudo da realidade da região -, passa pelo entendimento de que esta é uma representação e, como tal, depende profundamente do conhecimento e do reconhecimento dos seus agentes. É o que ocorre no cordel a seguir, "Quadras ao Roraimeira":

Foi numa noite feliz

Que a história começou

A estrela dessa terra

No céu inteiro brilhou.

Era o Trio Roraimeira

Que mostrava o seu valor

Cantando a nossa terra

Makunaimando o amor.

Cruviana trouxe Neuber

Mestre que é u-cho-à parte

Do buriti com farinha

A maloca virou arte.

Na dança do Parixara

De Pacaraima ao Bonfim

Veio o cavalo selvagem

Com o poeta Eliakim.

Zeca Preto cá chegou 


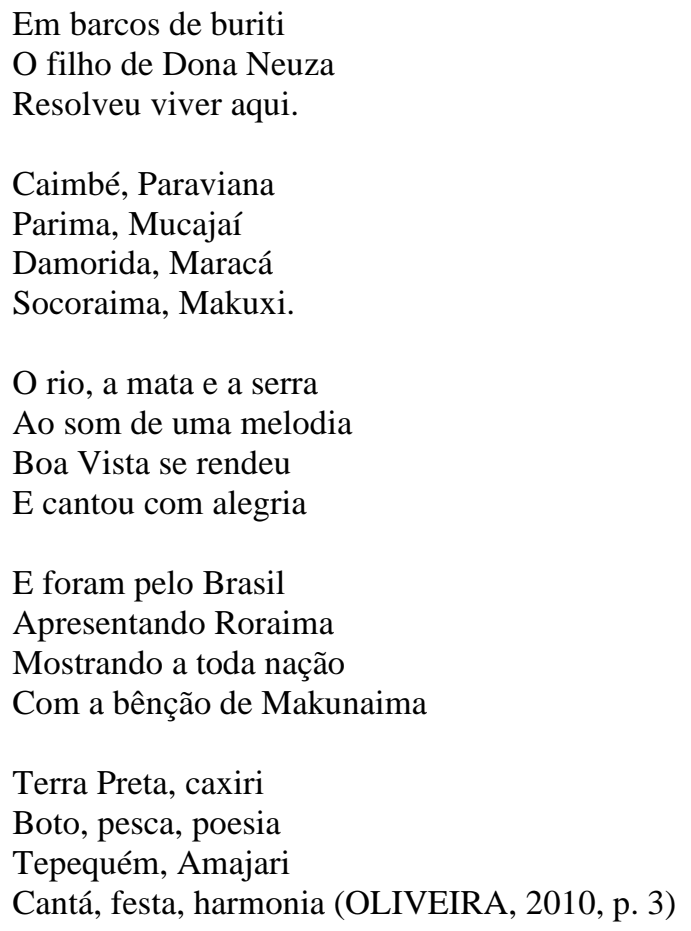

A linguagem utilizada no texto em análise é simples, direta, com rimas e estrofes curtas, propõem o ritmo rápido dos "acontecimentos", misturam a história do movimento cultural aos elementos que constroem a imagem local. Das nove estrofes de quatro versos, oito apresentam rimas intercaladas compondo o segundo e o último verso de cada estrofe, característica cordelística que garante a musicalidade, mantém o espectador atento. O texto, na primeira estrofe, compara o surgimento do trio a algo irradiador de luz, toma o espaço e passa a existir não só para a região, mas compõe-se numa arte conhecida e reconhecida por todos. Algo divino, semelhante ao nascimento do Cristo, uma vez que faz referência à popularmente conhecida canção "Noite feliz", exaltando a música e a poesia do "Trio Roraimeira", marcando o nascimento e exponenciando a importância das ações do grupo rumo à construção ou reconhecimento de uma identidade nortista. Nos versos "A estrela dessa terra/No céu inteiro brilhou" notamos a metáfora, também popularmente conhecida de "estrela" como emblema de "sucesso" em determinado ambiente artístico, se articula com a ideia de astro celeste mítico que ilumina e guia, leva a arte da região para o bem da humanidade, para "salvá-la" do desconhecimento. Dessa forma, afirma a cultura nortista e a faz brilhar nos mais diversos cenários, como a estrela de Belém.

$\mathrm{Na}$ estrofe seguinte, o trio é apresentado aos leitores/ouvintes novamente como agente de valorização cultural. O verso "Makunaimando o amor" introduz o personagem mítico de povos indígenas da região, como os pemon, indígenas habitantes do extremo norte da América 
do Sul, na tríplice fronteira entre Brasil, Venezuela e Guiana, região etnograficamente designada como "circum-roraima" (CARVALHO, 2015). Tal referência articula as identidades indígenas "originárias" da região às propostas deste movimento, trazendo à tona toda sua história, desde a colonização. Apresenta, dessa forma, o reconhecimento e a aproximação das tradições indígenas para a construção da identidade simbólica.

Mais especificamente, na terceira, quarta e quinta estrofes, o poeta aponta poeticamente a história de cada um dos três componentes do movimento "Roraimeira". Utiliza elementos presentes na produção de cada um, respectivamente, a música "Cruviana" (UCHOA, 2000), escrita por Neuber Uchôa, o poema “Cavalo Selvagem” (RUFINO, 2011), escrito por Eliakin Rufino e a presença do "buriti", ligada à produção musical de Zeca Preto e presente em pelo menos duas letras: a de "Makunaimando" (PRETO \& UCHOA, 2000) e "Do norte" (PRETO \& RUFINO, 2000), além de mencionar a origem migrante de Zeca, nascido no Pará (SILVA, 2013).

Na música de Neuber Uchôa, quase um "hino" cultural local, o compositor usa no refrão o prato indígena "damurida", o que transforma a "maloca" em arte, em representação da identidade de um estado nascente. Os referentes "Cruviana", "buriti”, "maloca", "farinha" colocam a linguagem do cordel à disposição desses elementos de identificações que compõem o imaginário da cultura popular que é assumida a partir de tal discurso.

Mencionando o poema que dá título ao livro de poemas Cavalo Selvagem (2011), associa-o à geografia da região, também com traços selvagens nas fronteiras de Bonfim com a Guiana e de Pacaraima com a Venezuela. Já a referência a Zeca Preto e às suas contribuições para a formação da identidade cultural, faz-se por meio de sua biografia e do buriti, fruto de uma palmeira comum ao Pará e a Roraima.

Ao apropriar-se, portanto, da gama de símbolos e de discursos do bojo do movimento "Roraimeira", o texto cordelístico em tela parece construir a cultura local, dela fazendo parte, no momento em que traz à tona alguns dos principais traços que a caracterizam, segundo o movimento cultural. O poeta, mais uma vez, articula gêneros (música, poesia e biografia) que "cantam" a cultura local, para, por meio destes, realizar o próprio "canto" à cultura roraimense. Todavia, seu próprio "canto" vem por meio de outro gênero textual, o cordel, apresentando nova leitura da produção do movimento "Roraimeira", agora re-lido por meio do olhar do cordelista.

Segundo Bourdieu (2012), dentre as forças em luta para a classificação e a definição da região, surge o "discurso regionalista", que tem uma característica performática, uma vez que 
busca se contrapor à definição dominante, inaugurando uma nova conceituação das fronteiras. Nesses discursos, podem ser utilizadas representações mentais (a língua, o dialeto ou o sotaque) ou representações objetais (emblemas, bandeiras, insígnias etc.), que se destinam a gerar a percepção prática social dos seus portadores.

\begin{abstract}
A eficácia do discurso performativo que pretende fazer sobrevir o que ele enuncia no próprio acto de o enunciar é proporcional à autoridade daquele que o enuncia: a fórmula "eu autorizo-vos a partir" só é eo ipso uma autorização se aquele que pronuncia está autorizado a autorizar, tem autoridade para autorizar. (BOURDIEU, 2012, p. 117)
\end{abstract}

Essa autoridade à qual o autor se refere está diretamente relacionada ao contexto da enunciação conceitual da região, da fronteira e de outros elementos simbólicos representativos dessas classificações. Para que o discurso do ente anunciador de uma identidade tenha legitimidade, é necessário que o grupo assim o reconheça, que sejam estabelecidas relações de pertinência, pois apenas dessa forma a existência de determinado grupo social fará sentido. É o que podemos observar nos versos "O rio, a mata e a serra/Ao som de uma melodia/Boa Vista se rendeu/E cantou com alegria", uma vez que os primeiros três elementos metaforizam a população do estado, assim como a cidade Boa Vista é metonímia deste. Podemos dizer, desse modo, que o cordel analisado aponta, nesses versos, para a formalização da existência desse espaço simbólico, que favoreça e justifique o jogo de poder que terá lugar a partir de então. Compreendemos, portanto, a importância de elementos como o discurso e a ideia de uma identidade regional como base para o reconhecimento e a legitimação de uma identidade que, antes de outras instâncias, é estabelecida no imaginário social dos seus componentes. Nesse sentido, Bourdieu declara que:

\begin{abstract}
...logo que a questão regional ou nacional é objectivamente posta na realidade social, embora seja por uma minoria actuante (que pode tirar partido de sua própria fraqueza jogando com a estratégia propriamente simbólica da provocação e do testemunho para arrancar réplicas, simbólicas ou não, que impliquem um reconhecimento), qualquer enunciado sobre a região funciona como um argumento que contribui - tanto mais largamente quanto mais largamente é reconhecido - para favorecer ou desfavorecer o acesso da região ao reconhecimento e, por este meio, à existência. (BOURDIEU, 2012, p. 120)
\end{abstract}

Entendemos, assim, que tanto o movimento "Roraimeira", quanto a produção cordelística de Rodrigo, interpretada por meio do cordel "Quadras ao Roraimeira”, apresentam a performance da cultura roraimense de modo a favorecer o acesso da região ao reconhecimento e à existência d" "A estrela dessa terra" que "No céu inteiro brilhou". Ao fazer valer a existência do espaço regional, demanda-se uma estratégia de reconhecimento, de afirmação pertinente, de um sentimento de forte ligação aos fatores, aos símbolos e às representações levantados como identificadores do lugar. 
$\mathrm{Na}$ análise empreendida, tal acontecimento se dá pela referência também aos elementos: "Caimbé", planta típica da região, "Damorida", comida típica, "Parixara”, dança indígena da região, "Caxiri”, bebida típica, "Maracá”, ilha que congrega uma importante estação ecológica; dentre outros. Na proporção em que se fortalecem os laços, na medida em que são estabelecidas lutas e união de forças para reivindicar a posse simbólica desse conjunto de significados, dá-se, então, a legitimação, de fato, do conceito em pauta.

$\mathrm{Na}$ verdade, torna-se, no caso roraimense, de uma estratégia simbólica de reconhecimento da região. O que ocorre porque predomina no texto a intencionalidade, como já anteriormente mencionado, da invenção de um discurso com tônica de regionalismo, não apenas no sentido de exaltar o que existe de exótico, de exuberante no lugar, mas também de afirmar, diante do restante do país, a tomada de posição concernente a essa identidade regional, colocando, tanto a literatura e a música, dentro do espaço nacional, como as marcas de tal identidade.

\section{Considerações finais}

A cultura tem características de multiplicidade, de fluidez e, portanto, de um grande leque de interações possíveis. Destarte, lembramos que após o estabelecimento da ideia de região com suas características culturais, outras se farão presentes e, à medida que tal representação de identidade simbólica não mais for suficiente para (re)apresentá-la, outros conjuntos de relações apontarão para novas imagens simbólicas.

A ideia de identidades em movimento contínuo, defendida por Hall (2006), apresenta uma relação de proximidade com o entendimento de Bourdieu (2012), também concebida como pluralmente constituída. Nesse sentido, o autor afirma:

\footnotetext{
Uma vez que a identidade muda de acordo com a forma como o sujeito é interpelado ou representado, a identificação não é automática, mas pode ser ganhada ou perdida. Ela tornou-se politizada. Esse processo é, às vezes, descrito como constituindo uma mudança de uma política de identidade (de classe) para uma política de diferença. (HALL, 2006, p. 21)
}

Tal diferença pode ser um elemento importante na constituição da identidade cultural do estado de Roraima, contrapondo o posicionamento popular anterior de uma "terra sem representação de identidade cultural". A partir do entendimento da constituição das sociedades pós-modernas, compreende-se que os mesmos motivos que levaram ao surgimento da negação, consolidam-se hodiernamente como as bases da realidade cultural dessa região. 
É com base nessa compreensão, bem como no entendimento das ideias de região e de cultura, aqui discutidas, que se pode compreender a existência, nos versos do texto cordelístico "Quadras ao Roraimeira", de uma concepção regional, destinada a afirmar a existência e aceitação do caráter peculiar da "Terra de Makunaima".

\section{Referências}

ANDRADE, Carlos Henrique Salles. Feira de Versos - Poesia de Cordel. 1. ed. São Paulo: Ática, 2005. v.1. 136p.

BARBOSA, Reinaldo Imbrósio. Ocupação em Roraima. I. Do Histórico Colonial ao Início do Assentamento Dirigido. Boletim do Museu Paraense Emílio Goeldi, 9(1): 123-144. Belém, 1993-1.

BATISTA, Sebastião Nunes. Antologia da Literatura de Cordel. São Paulo: Fundação José Augusto, 1997.

BOURDIEU, Pierre. O poder simbólico. 16. ed. Rio de Janeiro: Bertrand Brasil, 2012.

CARVALHO, Fábio Almeida de. Makunaima/Macunaíma: contribuições para o estudo de um herói transcultural. 1.ed. Rio de Janeiro: E-papers, 2015.

DIÉGUES JR., Manuel. Ciclos temáticos na Literatura de Cordel. Literatura popular em verso, estudos. Rio de Janeiro: Ministério da Educação e Cultura/Fundação Casa de Rui Barbosa, 1973.

GALVÃO, Ana Maria de Oliveira. Cordel: leitores e ouvintes. 1. ed. Belo Horizonte: Autêntica, 2006.

HALL, Stuart. A identidade cultural na pós-modernidade. 11. ed. Rio de Janeiro, RJ: DP \& A, 2006.

Da diáspora: identidades e mediações culturais. Belo Horizonte: UFMG, 2003.

Identidade cultural e diáspora. In: Revista do Patrimônio Histórico e Artístico Nacional. Rio de Janeiro, IPHAN, 1996, pp. 68-75

HAURÉLIO, Marcos. Literatura de Cordel: do sertão à sala de aula. São Paulo: Paulus, 2013.

INSTITUTO BRASILEIRO DE GEOGRAFIA E ESTATÍSTICA (IBGE). Censo Brasileiro de 2010. Rio de Janeiro: IBGE, 2012.

OLIVEIRA, Rafael da Silva; WANKLER, Cátia Monteiro; SOUZA, Carla Monteiro. Identidade e Poesia Musicada: Panorama do Movimento Roraimeira a partir da cidade de Boa Vista como uma das Fontes de Inspiração. Revista Acta Geográfica (UFRR), ano iii, n6, jul./dez. de 2009. pp. 27-37.

OLIVEIRA, Rodrigo Leonardo Costa de. Quadras ao Roraimeira. Lavradeiro. Literatura de Cordel. Recife-PE: Folhetaria Campos de Versos, 2010. Lavrados e Cordéis. Boa Vista: UERR ed., 2017. 
PRETO, Zeca; RUFINO, Eliakin. Do norte. In: PRETO, Zeca; RUFINO, Eliakin; UCHÔA, Neuber. $O$ canto de Roraima e suas influências indígenas e caribenhas. Manaus: Roraimeira Produções / SESC-RR, 2000. 1 CD. Faixa 01.

PRETO, Zeca; UCHÔA, Neuber. Makunaimando. In: PRETO, Zeca; RUFINO, Eliakin; UCHÔA, Neuber. $O$ canto de Roraima e suas influências indígenas e caribenhas. Manaus: Roraimeira Produções / SESC-RR, 2000. 1 CD. Faixa 16.

RUFINO, Eliakin. Cavalo Selvagem. Organização e apresentação de Tenório Telles. Manaus: Valer, 2011.

SARAIVA, António José, LOPES, Óscar. História da Literatura Portuguesa. 15. ed. Porto: Porto, 1989.

SILVA, Jessica Carla da. Roraima na década de 1980: O debate artístico e cultural. Boa Vista: UFRR, 2013.

UCHÔA, Neuber. Cruviana. In: PRETO, Zeca; RUFINO, Eliakin; UCHÔA, Neuber. O canto de Roraima e suas influências indígenas e caribenhas. Manaus: Roraimeira Produções / SESCRR, 2000. 1 CD. Faixa 10.

WANKLER, Cátia Monteiro. Da utopia à heterotopia: a ideia de "periferia" e os estudos de Literatura de Roraima. In: SOUZA, Carla Monteiro de; NETO, Lourival Novais; LEAL, Maria do Socorro Pereira; OYAMA, Maria Helena Valentim Duca; CRUZ, Maria Odileiz Sousa. (Org.). Estudos de Linguagem e Cultura Regional: vertentes poéticas e linguísticas. Boa Vista: Ed. UFRR, 2013. pp. 57-76.

Recebido em 25 de junho de 2019. Aceito em 25 de março de 2020. 